\title{
Overview of company EKSPLA and products offered
}

\section{G. Kudaba}

Ekspla UAB, Savanoriu av. 237, Vilnius, LT-02300, Lithuania

The Lithuanian laser manufacturer Ekspla was founded in 1992 as the 11 people spin-off of the laser division from the parent company EKSMA founded in 1983 as a pilot plant at the Institute of Physics.

The first laser made by Ekspla was the picosecond laser PL2140, delivered to the Japanese customer in 1993.

Soon after that, Ekspla gained worldwide recognition as the manufacturer of high performance solid-state $\mathrm{Nd}$ :YAG lasers, especially of picosecond and nanosecond time domains, as well as widely tunable parametric generators, SFG, and other nonlinear spectroscopy set-ups. This was confirmed by the "Prism Awards for Photonics Innovation" grant, which was received for the development of the NT200 tunable nanosecond tunable system in the 2011 year.

Through continuous growth, Ekspla has developed to 120 employees company with more than 18 Ph.D.'s. EKSPLA actively participates in local and EU projects, investing more than $1.5 \mathrm{mln}$. EUR for research and development annually. EKSPLA is widely represented in the world through its broadly developed distribution network. With more than 2500 lasers sold, EKSPLA is well known among top universities and research institutions, like NASA, CERN, Max Planck Institute, Massachusetts Institute of Technology, JAXA, University of Cambridge and others.

EKSPA has been continuously growing its product portfolio and now is offering standard and specially designed lasers for the science and industry applications. Among others, it is worth to mention such installations as the most powerful 5.0 TW @ $880 \mathrm{~nm}, 1 \mathrm{kHz}, 9$ fs OPCPA system in ELI-ALPS, Hungary together with Light Conversion; the most powerful laser in the world 10 PW Extreme Light Infrastructure in the Czech Republic together with US company National Energetics; $160 \mathrm{~J}$ nanosecond Nd: phosphate glass laser in South Korea.

One of the recent EKSPLA developments is the NL740 series laser with highly stabile output parameters:

- Narrow bandwidth, stable, true SLM pulses

- Excellent pulse energy (typically $0.1 \%$ StDev @ $1064 \mathrm{~nm}$ ) and pulse duration stability

- Excellent spatial mode stability

- Excellent output power stability (typically $< \pm 0.5 \%$ peak-to-peak)

- $\quad 3-10$ ns tunable pulse duration

- $\quad$ Up to $100 \mathrm{~mJ}$ output energy

- $\quad$ Up to $100 \mathrm{~Hz}$ repetition rate

- $\quad 1064,532 \mathrm{~nm}$ or $355 \mathrm{~nm}$ output wavelength

- $\quad$ Reliable $24 / 7$ operation
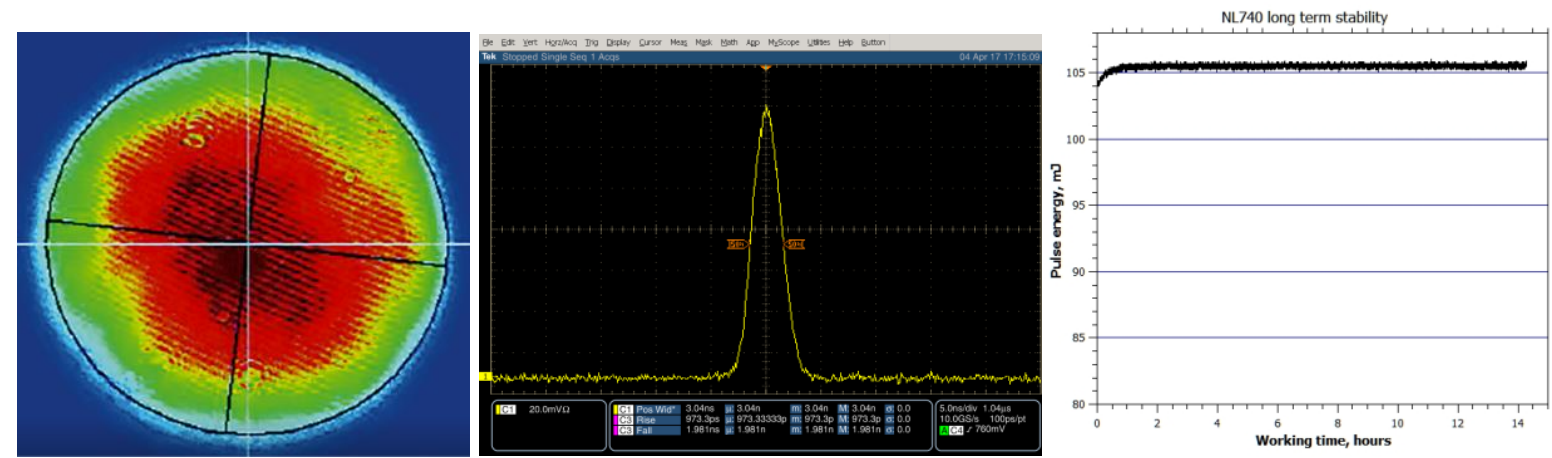

Fig. 1 The typical near field beam profile, pulse shape and long-term energy stability of NL740 series laser.

NL740 series laser (model NL940-100-SH/TH) was successfully installed for the Laser-Induced Damage Threshold (LIDT) application [1]. The company LIDARIS used it for investigation of UV optics reliability in the joint project "ESsential PREparation Steps for Qualification Longevity of Space Optics" (ESPRESSO, PECTS call, Contract Nr. 4000115898) with the European Space Agency (ESA/ESTEC).

\section{References}

[1] A. Melninkaitis, G. Batavičiūtè, C. Heeseb, M. Ščiuka, and L. Smalakys, "Towards qualification longevity of high power space optics," Proceedings of the SPIE, 11180, id. 111808512 pp. (2019). 